\title{
Style Analysis for Diversified US Equity Funds
}

\section{Andrew Mason (University of Surrey)}

is a Lecturer in Finance at University of Surrey and holds a PhD in Finance from the University of Southampton. He has 20 years' experience in the financial sector including positions as Economist and Investment Strategist at Nomura and Citicorp and senior investment management roles at USS, Kemper and Philips Pension Fund where he was head of equities. He was a top performance ranked investment manager before returning to academia.

\section{Frank McGroarty (Southampton University)}

is a Lecturer in Finance in the School of Management at the University of Southampton. He holds a PhD in International Finance from the University of Southampton. He has published a number of papers on international finance and financial derivatives. Prior to becoming an academic, he spent 13 years working in investment analysis and portfolio management.

\section{Steve Thomas (CASS)}

Is Professor of Finance at CASS and Visiting Professor, ISMA Centre, University of Reading. Previously he was Professor of Financial Markets, University of Southampton, Professor of Finance, University of Wales, Swansea, and Houblon-Norman Fellow, Bank of England. He has written numerous articles for academic journals and was ranked 11th in Europe for Finance Research. He is currently a Member of the Investment Committee of Hasley Investment Management, and previously a Director, Bear Stearns Global Alpha Macro Hedge Fund and a Director of Firecrest Hambro.

Corresponding author: andrew.mason@surrey.ac.uk

\begin{abstract}
In this study we consider two methods of returns based style analysis for classification of investment styles for a single asset class, US Diversified Equity Funds. We extend Sharpe's (1992) style Returns Based Style Analysis (RBSA) by forming style groups using cluster analysis and RBSA factors. We also introduce a parsimonious Best Fit Index (BFI) of style classification which explicitly acknowledges the existence of market segmentation and practitioner benchmarking. The methods provide complementary information about mutual fund returns. Both methodologies explain a significant proportion of the cross section of out of sample returns, but the BFI method performs better out-ofsample is more transparent and more closely aligned to investment practice.
\end{abstract}

Keywords: Style; Investment; Benchmark; Portfolio; Value; Factors 


\section{Introduction}

Despite general agreement that a range of differing investment styles does exist and despite similarities between descriptions of investor types, there is no uniformly accepted classification of equity styles and those most commonly used allow a wide range of strategies to be employed under the broad umbrella of their classification.

Our study focuses on a single but diversified asset class -US diversified equity funds, using a large sample of US mutual funds. We focus on two different methods of returns based style analysis and consider the implications for selection or appraisal of investment managers. We identify the different type of information provided by the two methods, economic exposure and index benchmarking, and compare the explanatory power of RBSA with style clusters and best fit indices in and out of sample.

Our findings confirm the continuing relevance of Returns Based Style Analysis (RBSA) but extend the usefulness of the findings by forming style groups on the basis of RBSA coefficients. Prior studies have focussed on individual funds or analysis of averages of funds defined by broad portfolio classifications such as 'prospectus objectives'. The formation of style groups greatly improved the usefulness of the output in terms of benchmarking or peer group analysis, the main purpose of style classification. Membership of style groups based on common characteristics explained a significant proportion of out of sample returns. The importance of identifying the correct benchmark is underlined by empirical evidence that fund flows follow outperformance of benchmark indexes, Gruber (1996) and Sirri and Tufano (1998), whilst Del Guercio and Tkac (2008) highlight the effect of Morningstar ratings on mutual fund flows, again supporting the importance of establishing the correct peer group as money flows to funds with the highest ratings in their category.

We also use a new parsimonious returns based model to establish which index was the 'Best Fit Index' (BFI) for each individual fund based on a series of OLS regressions against a wide range of 2 
style indices. Our BFI methodology overcomes one of the major criticisms of RBSA analysis, the lack of statistical transparency, as BFI indices were found to have very high levels of statistical significance. This approach also has intuitive appeal as funds are generally benchmarked against a particular index. Chan et al (2002) noted that funds tended to 'cluster' around a broad index such as the S\&P 500 but our analysis shows that actually they are clustered around a range of differentiated style indices. The BFI method meets the peer group and benchmarking criteria essential to classification of fund styles and explains the cross-sectional variation of out of sample returns better than the RBSA methodology. It may be considered as a special case of Sharpe's (1964) CAPM but instead of proxying the market portfolio with a broad index we seek to identify 'the market' or investment universe for each individual fund.

Our second approach to returns based style analysis is grounded in practitioners' tendency to explicitly or implicitly evaluate investment funds against an appropriate benchmark index. Chan et al (2009) among others note this industry practice and stress the importance of establishing the appropriate 'investment domain' for investment managers (see also; Lehman and Modest (1987) and Brown and Goetzmann (1997)). The evolution of the construction of benchmark indices has served to mitigate some of the concerns that Kuenzi (2003) raised about matching investors to an appropriate 'strategy benchmark' i.e. one that more closely reflects the fund's true investment universe. Kuenzi (2003) and Belden and Waring (2001) note that using an inappropriate benchmark leads to a built in tracking error and hinders evaluation using tools such as the information ratio. The concept of identifying the correct index is also highlighted by recent work by Cremers and Petajisto (2009) and Cremers et al (2010) who use a range of indices for their analysis of active management.

We evaluate both methods of style classification, RBSA and BFI, against out of sample returns following the approach of Brown and Goetzmann (1997) to establish the extent to which either methodology can provide useful information for peer group analysis or benchmarking. 
Here we assess two alternative methods of returns based style analysis for the purpose of benchmarking and peer group analysis; essential functions for the selection, evaluation and attribution of investment funds. To this end we modify Sharpe's (1992) RBSA methodology by forming style groups using RBSA factors and we use a modified version of the CAPM model by selecting the appropriate 'market' or investment domain for individual funds. The format of the paper is as follows: section 2 describes the data and methodology, section 3 outlines the styles formed, section 4 discusses our out of sample model and section 5 provides a summary and our conclusions.

\section{Data \& Methodology}

\section{Data}

We use a large database of U.S. Diversified Equity Funds supplied by Morningstar, for our Mutual Funds Portfolio Returns data base; data are monthly total returns data for the period 1996-2005. We screen the mutual fund data to exclude multiple share classes and to exclude index funds; this results in a database which ranges from 763 funds in the early period to 1,930 funds in 2005 . The importance of adjusting for multiple share classes is underlined by data from the Investment Company Institute (2011) where 4,586 mutual funds were observed to have 11,824 fund share classes in 2005; there is no systematic relationship between the number of funds and the number of share classes.

We use US style indices provided by Russell U.S. Equity Indices and Standard \& Poor's U.S. Equity Indices and again use monthly total returns data for the period 1996-2005. Our study period was selected on the basis of availability of style index data because although some style indices were available before this date, a wide range of indices is only available as far back as 1996 when Standard \& Poor's introduced a range of 'pure' style indices. We use 12 Russell indices and 15 
Standard \& Poor's indices for our Best Fit Indices (BFI) analysis (see Appendix 2: Stock Market Indices for details).

\section{RBSA Methodology}

In Sharpe's (1992) original analysis he used a wide range of asset classes, including four U.S. equity indices, befitting the nature of his diverse fund sample. In our analysis which is confined to U.S. equities, we use four stock indexes: Russell 1000 Growth, Russell 1000 Value, Russell 2000 Growth and Russell 2000 Value. These indices are the most commonly used indices for this type of analysis and the most widely used by practitioners for benchmarking in the U.S. equity market. The Sharpe conditions, that the set of indices used for RBSA is exhaustive and exclusive, i.e. cover the full market and no stock is represented in more than one index, leads to some compromises. These conditions in practice restrict analysis to one index provider per asset class but also mean that the full range of indices by any provider for that asset class cannot be included in any individual RBSA estimation as indices are not exclusive with respect to their constituents e.g. Russell 1000 comprises Russell 1000 Growth and Russell 1000 Value but it also includes the stocks represented in Russell Top 200 and by implication Russell Top 200 Growth and Russell Top 200 Value. Thus one of the problems with RBSA analysis and the selection of indices is the dilemma of whether the core market index e.g. the Russell 1000 should be included or its component style indices Russell 1000 Growth and Russell 1000 Value should be included as to include both would breach the exclusivity condition. We have chosen to use the Growth and Value versions of the Russell indices although we have reservations about excluding core indices as many funds employ a core strategy which has to be artificially constructed from a combination of growth and value indexes when a single index might perform the same function efficiently'.

The model we employ is the standard Sharpe (1992) style RBSA model the 'strong' version of RBSA with the portfolio restriction i.e. coefficients sum to one (equation 2) and the short-sales restriction 
i.e. negative coefficients of the factors are not allowed (equation 3). For further discussion of these issues see ter Horst et al (2004) and Swinkels and Van der Sluis (2006) or Becker (2003). Studies focussing on stylised refinements to the statistical process use very small samples for their empirical tests and often are not suitable for dealing with a single diversified asset class; Kim et all (2005) use 2 U.S. funds, ter Horst et al (2004) use 18 international mutual funds, whilst Swinkels and Van der Sluis (2006) use 12 international funds and 87 asset allocation funds, in contrast to the large sample used in our study. Our contribution is to increase the usefulness of the RBSA results by forming style groups based on similarities in factor exposure.

Our version of the Sharpe model is as follows:

$e_{i}=R_{i}-\left(b_{i 1} F_{1}+b_{i 2} F_{2}+\ldots+b_{i n} F n\right)$

Where:

$e_{i}=$ tracking variance; the difference between the fund return and the passive style portfolio

$F_{1} . . F n=$ asset classes i.e. Russell 1000 Growth, Russell 1000 Value, Russell 2000 Growth and Russell 2000 Value

$b_{i 1} F_{1}+b_{i 2} F_{2}+\ldots+b_{i n} F n=$ passive style portfolio

$R_{i}=$ fund return

With the restrictions:

$$
\begin{aligned}
& \sum_{i=1}^{n} \beta_{i}=1 \\
& \beta_{i} \geq 0, i=1, \ldots, n
\end{aligned}
$$

In our Sharpe style model we run the RBSA optimisation for 36 month periods and repeat the process for each period ending Dec 1998 to Dec 2005; Sharpe used a period of 60 months in his original 1992 study but this 'average' exposure is unlikely to capture nuances of style and strategy over a stock market cycle as noted by Christopherson (1995) and others. We thus end up with the large number of 'individual' fund investment styles ranging from 763 based on the formation period 1996-98 to 1,930 based on the period 2003-05. For each fund the style information illustrated in Table 1 is generated by the RBSA model but in varying proportions depending on the estimated 6 
exposure to the returns of the various indices, what Sharpe (1992) termed 'the economic exposure' to those factors. Whilst this information is useful for analysis of an individual fund it is does not serve the benchmarking function against either a known index or a peer group. We address this issue of multiplicity of styles by forming style clusters based on the RBSA coefficients i.e. the hypothetical index weightings that would be held in a passive Sharpe index.

In order to utilise the results of our RBSA style analysis in the context of style classification, bearing in mind the purpose of style analysis i.e. peer evaluation and performance attribution, we use kmeans cluster analysis to form 'style groups' based on the index coefficient weightings created by the Sharpe model. We classify funds into nine groups, in line with the Morningstar Stylebox (See Kaplan et al (2003)). The RBSA results do not fit exactly into the style box format as due to the exclusivity restrictions we do not use mid-cap indices or 'core' indices such as the Russell 1000 . This cluster methodology forms groups on the basis of most similar characteristics; the characteristics in this case being the weighting attached to the Russell indices. We undertake the analysis for each set of 36 months results and produce a set of independent clusters each time. Because each set of clusters is formed individually, groups may differ from year to year.

\section{Best Fit Index (BFI) Methodology}

As an alternative method of returns based style analysis we consider whether a single 'Best Fit Index' can adequately represent funds various investment styles. This method has intuitive appeal because we know that funds are often explicitly benchmarked against a stock market index. In order to establish whether the Russell and Standard \& Poor's indices can explain a large proportion of the monthly returns of our sample of mutual funds we run individual regression analysis for each fund in our sample against twenty seven Russell and Standard \& Poor's U.S. equity indices encompassing the full range of style and value-growth permutations. We record the highest $r^{2}$ or best-fit index for each fund to create our Best Fit Index (BFI) sample. We use our BFI sample for comparison with our RBSA 
styles both in and out of sample to address the question whether these more sophisticated style indices reflect the cross section of returns of our mutual fund sample as well or better than our RBSA model. The methodology is outlined below.

For each mutual fund we run an Ordinary Least Squares regression (equation 4) for a 36 month period against twelve Russell Indices and fifteen Standard \& Poor's indices' monthly returns to establish which individual index provides the best explanation or best fit of each individual fund's returns.

$$
r_{i t}=\alpha_{i}+\beta R_{I t}+\epsilon_{i t}
$$

Where: $r_{i t}=$ return on fund $i$ for month $t, \alpha_{i}=$ alpha, $R_{I t}=$ return on index $I$ for month $t$; $I$ is calculated individually for each of the 27 Russell or $S \& P$ indices, $\in_{i t}=$ error term

Thus for each fund in the sample, e.g. 1,930 funds for the period Jan 2003 to Dec 2005, the index with the highest $r^{2}$ is selected from twenty seven sets of regression results and we record the index name and it's $r^{2}$. This process is repeated for each year end from 1998-2005. Thus we have eight sets of results based on 36 months returns as in the RBSA analysis.

The two methodologies we employ aim to capture different things and thus provide complementary information. Sharpe's (1992) RBSA aims to minimise tracking variance relative to a set of asset classes or factors whereas our Best Fit Index methodology uses a number of OLS regression to identify a single stock market index or factor which fits the return profile of a fund best over periods under analysis." We next consider the style groups formed by these returns based methodologies and their usefulness in explaining the cross section of out-of-sample fund returns. 


\section{Return Based Style Analysis}

\section{RBSA Styles}

Sharpe (1992) observed that many of the differences in U.S. equity mutual fund returns could be attributed to their exposures to four U.S. equity indexes representing Large-Capitalization Value Stocks, Large-Capitalization Growth Stocks, Medium-Capitalization Stocks and Small-Capitalization Stocks. The variability in these index returns was found to be greater from year to year than randomly formed security groups, and as fund exposures across these asset classes varied greatly Sharpe (1992) attributed a significant proportion of fund returns to the combined effect of the returns on asset classes and exposure to those assets. He developed the RBSA model to capture the 'estimated' average exposure to those asset classes based on historic fund returns. Sharpe (1992) style RBSA uses the returns on a collection of equity indices, (the factors), to replicate an investment manager's investment style based on the returns of the investment portfolio and an optimised portfolio of indexes. This passive portfolio of index weights based on average style exposure to those index returns over the period under review is then regarded as the investment manager's style or 'style benchmark'. This may be replicated in the future by the weighted combination of indexes prescribed by the model. The proportion of fund returns explained by the model in terms of the coefficient of determination, $r^{2}$, is the fund's estimated 'style' and the proportion unexplained by the model is termed 'selection' and covers all deviations from the passive index. (For a detailed explanation of the methodology see Ben Dor et al (2003))

Table 1 illustrates how style groups may be formed using what Sharpe (1992) identifies as the 'economic exposure' of funds to the Russell indexes. We have where possible described the styles in accordance with typical Stylebox classifications. Large-Cap core funds comprise similar proportions of the Russell 1000 Growth and the Russell 1000 Value, as the Russell 1000 has to be excluded, as did the Russell Mid-Cap indices, to satisfy the exclusivity requirement for stocks. 
Table 1: RBSA Style Clusters 1998 and 2005

\begin{tabular}{|c|c|c|c|c|c|c|c|}
\hline Style 1998 & Index & Weight & $\%$ & Style 2005 & Index & Weight & $\%$ \\
\hline Large-Cap Growth & r1000gr & 0.77 & $13.1 \%$ & Large-Cap Growth & r1000gr & 0.80 & $14.7 \%$ \\
\hline \multirow{2}{*}{ Growth } & r1000gr & 0.45 & \multirow{2}{*}{$16.0 \%$} & \multirow{2}{*}{ Growth } & r1000gr & 0.47 & \multirow{2}{*}{$12.5 \%$} \\
\hline & 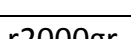 & 0,1 & & & rangar & 011 & \\
\hline & & & & & & & \\
\hline \multirow{3}{*}{ Small-Cap Growth } & r2000gr & 0.84 & \multirow{3}{*}{$16.0 \%$} & \multirow{3}{*}{ Small-Cap Growth } & r2000gr & 0.81 & \multirow{3}{*}{$14.1 \%$} \\
\hline & & & & & & & \\
\hline & r2000va & 0.07 & & & r2000va & 0.05 & \\
\hline \multirow{3}{*}{ Large-Cap Core } & r1000gr & 0.49 & \multirow{3}{*}{$17.9 \%$} & \multirow{3}{*}{ Large-Cap Core } & r1000gr & 0.49 & \multirow{3}{*}{$18.6 \%$} \\
\hline & & & & & & & \\
\hline & r1000va & 0.43 & & & r1000va & 0.46 & \\
\hline \multirow{3}{*}{ Large-Cap Value } & r1000va & 0.70 & \multirow{3}{*}{$12.0 \%$} & \multirow{3}{*}{ Large-Cap Value } & r1000va & 0.65 & \multirow{3}{*}{$9.8 \%$} \\
\hline & & & & & & & \\
\hline & r2000va & 0.15 & & & r2000va & 0.02 & \\
\hline \multirow{3}{*}{ Large-Cap Value } & r1000va & 0.93 & \multirow{3}{*}{$11.6 \%$} & \multirow{3}{*}{ Large-Cap Value } & r1000va & 0.86 & \multirow{3}{*}{$14.9 \%$} \\
\hline & & & & & & & \\
\hline & r2000va & 0.05 & & & r2000va & 0.03 & \\
\hline \multirow{3}{*}{ Value } & r1000va & 0.44 & \multirow{3}{*}{$5.9 \%$} & \multirow{3}{*}{ Value } & r1000va & 0.33 & \multirow{3}{*}{$8.0 \%$} \\
\hline & & & & & & & \\
\hline & r2000va & 0.48 & & & r2000va & 0.36 & \\
\hline \multirow{3}{*}{ Small-Cap Value } & r1000va & 0.10 & \multirow{3}{*}{$9.3 \%$} & \multirow{3}{*}{ Small-Cap Value } & r1000va & 0.11 & \multirow{3}{*}{$8.2 \%$} \\
\hline & r2000gr & 0.17 & & & r2000gr & 0.22 & \\
\hline & r2000va & 0.68 & & & r2000va & 0.63 & \\
\hline \multirow{5}{*}{ Diverse } & r1000gr & 0.16 & \multirow{5}{*}{$5.8 \%$} & \multirow{5}{*}{ Diverse } & r1000gr & 0.07 & \\
\hline & r1000va & 0.38 & & & r1000va & 0.47 & \\
\hline & & & & & & & $9.3 \%$ \\
\hline & r2000gr & 0.30 & & & r2000gr & 0.38 & \\
\hline & r2000va & 0.15 & & & r2000va & 0.07 & \\
\hline Sample & & & 763 & Sample & & & 1930 \\
\hline
\end{tabular}

Coefficients are estimated using the RBSA methodology for the period 1996-98 for the 1998 clusters and for the period 2003-2005 for the 2005 clusters; funds are assigned to 9 clusters for each period on the basis of k-means cluster analysis which maximises the similarities of index coefficients within clusters. 
RBSA model: $e_{i}=R_{i}-\left(b_{i 1} F_{1}+b_{i 2} F_{2}+\ldots+b_{i n} F n\right)$

Where; $e_{i}$ = tracking variance, $F_{1} \ldots F n=$ asset classes, $b_{i 1} F_{1}+b_{i 2} F_{2}+\ldots+b_{i n} F n$ = passive style portfolio and $R_{i}=$ fund return.

Style is descriptive and based on the mean index weights estimated by the RBSA model for each style cluster.

Index lists key index coefficients estimated by RBSA where; r1000gr =Russell 1000 Growth, r1000va = Russell 1000 Value, r2000gr =Russell 2000 Growth and r2000va = Russell 2000 Value. Estimation periods based on 36 monthly returns are illustrated .e.g. 1996-98 with dominant index weights highlighted in bold, Sample shows the number of funds in the sample for the estimation period, and \% is the percentage of those funds within individual style clusters.

The close similarity between the styles in 1998 and 2005 is partly coincidental as the style groups may differ from year to year but overall, given the freedom of choice in formation of clusters the RBSA model does a good job of picking up many style categories. The style categories, as illustrated in Table 1, are represented in all eight periods; Large-Cap Growth, Growth, Small-Cap Growth, LargeCap Core and Large-Cap Value, whilst Value and Small-Cap Value are represented seven out of eight times and Small-Cap five times. There is also a style which we have labelled 'Diverse', because its exposure seems to be spread across all indices; perhaps in an attempt to estimate the exposure of Mid-Cap Core fundsiii. The RBSA methodology minimises the variance between the funds and the combination of indices and Table 1 may indicate for example, that the different groups of 'Large-Cap Value' funds may react more or less to movements in small cap value indices thus complementing information which may be generated by establishing which market index best fits a funds returns.

\section{Best Fit Index Styles}

The concept of a benchmark index is widely used in practice and in recent years all index providers have moved towards more complex methods of construction which reflect underlying stocks 'growth-value orientation' and the fact that different index 'styles' have a different risk return pattern. We also note Lehmann and Modest's (1987) findings that it is important to establish the appropriate model for benchmarking and risk-return analysis and Chan et al's (2009) revelations 
concerning different benchmarks. We assign each fund to a BFI group on the basis of a 36 month OLS regression of monthly fund returns against individual index returns and select the index which best explains the index over that period, in terms of the highest coefficient of determination (See Appendix 3: Best Fit Indices for details). The results for all twenty seven Russell and S\&P U.S. Equity indices are sorted based on the correlation between indices of the same 'style' and we have organized them into nine categories divided on the basis of size and style, in accordance with the typical Stylebox breakdown. The results for the period 1996-2005 are illustrated in Table 2 which allows us to make some preliminary observations on the sample and the resulting styles.

We explicitly acknowledge the existence of market segmentation and by using this simple and parsimonious model try to establish which index most closely resembles an individual mutual fund's investible universe i.e. which benchmark index is representative of the 'universe' for that fund. Once the correct benchmark is established it is possible the more accurately estimate value added performance and risk e.g. calculation of information ratios or active risk. 
Table 2: Overview of Best Fit Style Indices 1996-2005

\begin{tabular}{|l|r|r|r|r|r|r|r|r|}
\hline BFI Index Style & $1996-98$ & $1997-99$ & $1998-00$ & $1999-01$ & $2000-02$ & $2001-03$ & $2002-04$ & $2003-05$ \\
\hline Large-Cap Growth & $14.9 \%$ & $14.5 \%$ & $15.6 \%$ & $11.9 \%$ & $10.7 \%$ & $11.0 \%$ & $9.5 \%$ & $14.1 \%$ \\
\hline Large-Cap Core & $21.7 \%$ & $22.1 \%$ & $21.0 \%$ & $22.5 \%$ & $23.7 \%$ & $26.3 \%$ & $24.7 \%$ & $21.4 \%$ \\
\hline Large-Cap Value & $12.8 \%$ & $12.0 \%$ & $15.4 \%$ & $14.1 \%$ & $14.6 \%$ & $13.7 \%$ & $15.4 \%$ & $14.1 \%$ \\
\hline Mid-Cap Growth & $14.5 \%$ & $14.9 \%$ & $12.7 \%$ & $14.9 \%$ & $14.3 \%$ & $13.9 \%$ & $11.9 \%$ & $10.0 \%$ \\
\hline Mid-Cap Core & $7.1 \%$ & $7.3 \%$ & $6.2 \%$ & $7.1 \%$ & $7.4 \%$ & $8.8 \%$ & $8.9 \%$ & $8.9 \%$ \\
\hline Mid-Cap Value & $6.2 \%$ & $5.7 \%$ & $9.2 \%$ & $8.7 \%$ & $8.9 \%$ & $5.4 \%$ & $4.4 \%$ & $6.9 \%$ \\
\hline Small-Cap Growth & $9.9 \%$ & $10.7 \%$ & $10.2 \%$ & $10.6 \%$ & $11.0 \%$ & $8.4 \%$ & $11.7 \%$ & $11.9 \%$ \\
\hline Small-Cap Core & $4.6 \%$ & $5.0 \%$ & $4.5 \%$ & $4.2 \%$ & $3.9 \%$ & $6.8 \%$ & $8.2 \%$ & $6.5 \%$ \\
\hline Small-Cap Value & $8.3 \%$ & $7.9 \%$ & $5.1 \%$ & $6.2 \%$ & $5.5 \%$ & $5.8 \%$ & $5.4 \%$ & $6.2 \%$ \\
\hline Total & $100 \%$ & $100 \%$ & $100 \%$ & $100 \%$ & $100 \%$ & $100 \%$ & $100 \%$ & $100 \%$ \\
\hline Sample & 763 & 908 & 1,126 & 1,295 & 1,457 & 1,650 & 1,736 & 1,930 \\
\hline
\end{tabular}

Source: Morningstar monthly returns data.

BFI model: ${ }^{r} \mathbf{1}=\alpha+\beta R_{1}+\epsilon_{1}$

Where; ${ }^{r} \mathbf{1}=$ return on fund $1, \alpha=$ constant, $\beta R_{1}=$ return on index 1 and $\boldsymbol{E}_{\mathbf{1}}=$ net effect of all other unobservable factors

The results show the proportion of funds allocated to a particular BFI Index Style based on OLS regressions of individual funds against each of the 12 Russell Indices and 15 Standard \& Poor's indices' fund for the 36 month in-sample period noted from which the Best Fit index $(\mathrm{BFI})$ is selected.

Large-Cap Growth: Russell Top 200 Growth, Russell 1000 Growth, S\&P500 Growth, S\&P500 Pure Growth. Large-Cap Core:Russell Top 200, Russell 1000, S\&P500. Large-Cap Value: Russell Top 200 Value, Russell 1000 Value, S\&P500 Value, S\&P500 Pure Value.

Mid-Cap Growth: Russell Midcap Growth, S\&P400 Growth, S\&P400 Pure Growth. Mid-Cap Core:Russell Midcap, S\&P400. Mid-Cap Value: Russell Midcap Value, S\&P400 Value, S\&P400 Pure Value.

Small-Cap Growth: Russell 2000 Growth, S\&P600 Growth, S\&P600 Pure Growth. Small-Cap Core: Russell 2000, S\&P600. Small-Cap Value: Russell 2000 Value, S\&P600 Value, S\&P600 Pure Value. 
The first thing to note is the very large increase in sample size over the period under review; the sample size increases from 763 in the 1996-98 estimate period to 1,930 in the 2003-05 period, an increase of $253 \%$. The following broad trends may be noted; Large-Cap Core funds grew in line with overall growth in the sample, with growth in Large-Cap Growth slightly below trend and Large-Cap Value growing above trend. At the Mid-Cap level we see very strong growth of Mid-Cap Core (317\%) and strong growth in the Mid-Cap Value segment, with Mid-Cap Growth proving to be the least popular category of all segments (up 174\%). The picture at the Small-Cap level is more intriguing with Small-Cap Core exhibiting the strongest growth of all segments (up 357\%) and Small-Cap Growth showing very strong performance whilst Small-Cap Value grew much more slowly (up 189\%). Anecdotally we know that there was a move from very large cap growth styles into value based and small cap styles in the wake of the bursting of the 'Technology, Media, Telecom' bubble. We now compare the results of our RBSA style groups and our BFI style groups both in and out of sample.

\section{Discussion of Results for RBSA and BFI Styles}

Both methods of style analysis use the same 36 months' estimation periods; what differs between them is the method of estimating style and the style information provided. Table 3 illustrates the basic information which is generated for an individual fund by these processes. It illustrates some of the properties of the methodologies and why they may be complementary given the different types of information they provide. In this example the BFI model correctly identifies the benchmark fund of the Goldman Sachs Mid-Cap Value fund as the Russell Midcap Value Index (as stated by the fund managers), with a high level of statistical confidence, whereas the RBSA method estimates a synthetic average economic exposure based on returns of the Russell 1000 Value Index and the Russell 2000 Value Index to overcome the fact that the exclusivity constraint means that the Russell Midcap Value Index must be excluded if the model uses the Russell 1000 Value Index and the Russell 2000 Value Index. The problem is more prevalent when we consider that the Russell 1000 index, the 
core market index must be excluded if we use the Russell 1000 Growth Index and the Russell 1000 Value Index, as we estimate that this index is the benchmark for between $21 \%$ and $26 \%$ of funds for the period 1996-2005, depending on the sample size and estimation period (See Table 2 Overview of Best Fit Style Indices 1996-2005). 
Table 3:Single Fund Example of RBSA and Best Fit Index Data Dec 2005

\begin{tabular}{|l|l|}
\hline \multicolumn{2}{|l|}{ Goldman Sachs Mid-Cap Value Fund Dec 2005} \\
\hline RBSA data & $9 \%$ \\
\hline Russell 1000 Growth & $59 \%$ \\
\hline Russell 1000 Value & $0 \%$ \\
\hline Russell 2000 Growth & $32 \%$ \\
\hline Russell 2000 Value & 0.83 \\
\hline RBSA $r^{2}$ Dec 2005 & $83 \%$ \\
\hline Style & $17 \%$ \\
\hline Selection & 0.09 \\
\hline R** $<0.01$ & $0.96 * * *$ \\
\hline BFI Data & \\
\hline Best Fit Index & \\
\hline Russell Midcap Value beta & \\
\hline & \\
\hline & \\
\hline
\end{tabular}

Source: Morningstar and Russell monthly returns data.

Results of a single fund RBSA optimisation model using Russell 1000 Growth, Russell 1000 Value, Russell 2000 Growth and Russell 2000 Value and an OLS regression to select Best Fit Index against each of the 12 Russell Indices and 15 Standard \& Poor's indices'based on 36 monthly returns from Jan 2003-Dec 2005

RBSA model: $e_{i}=R_{i}-\left(b_{i 1} F_{1}+b_{i 2} F_{2}+\ldots+b_{i n} F n\right)$

Where; $e_{i}=$ tracking variance, $F_{1} \ldots F n=$ asset classes, $b_{i 1} F_{1}+b_{i 2} F_{2}+\ldots+b_{i n} F n=$ passive style portfolio and $R_{i}=$ fund return. BFI model: ${ }^{r} \mathbf{1}=\alpha+\beta R_{1}+\epsilon_{1}$

Where; ${ }^{r} \mathbf{1}=$ return on fund $1, \alpha=$ constant, $\beta R_{1}=$ return on index 1 and $\boldsymbol{E}_{\mathbf{1}}=$ net effect of all other unobservable factors

During the in-sample estimation period of thirty six months there seems to be little to choose between the models in terms of explaining a very high level of funds monthly performance for our 16 
sample of funds, as illustrated in Table 4, with the RBSA model generating marginally higher $r^{2}$ s in the early period and Best Fit Index selection recording marginally higher $r^{2 \text { s }}$ for the rest of the period. Unsurprisingly standard deviations of $r^{21} s$ are higher in estimation periods encompassing the equity market peak in 2000 and the subsequent crash. Although the magnitude of the in sample results is similar the BFI results have the advantage of statistical transparency. The mean $r^{2}$ for the BFI sample of 1,930 funds for the period 2003-05 is 0.89 with all funds significant at the $99 \%$ confidence level ( $p$ values $<0.01$ ) and with only $2 \%$ of the sample having an $r^{2}$ less than 0.60 . 
Table 4: Comparison of In-Sample Estimation Results for the RBSA and Best-fit Index Models for the Period 1996-2005

\begin{tabular}{|l|l|l|l|l|l|}
\hline Period & & & & & \\
& Sample & RBSA r & Std. Dev. & BFI r & Std. Dev. \\
\hline 1996 to 1998 & 763 & 0.89 & 0.08 & 0.91 & 0.08 \\
\hline 1997 to 1999 & 908 & 0.89 & 0.08 & 0.89 & 0.09 \\
\hline 1998 to 2000 & 1128 & 0.84 & 0.12 & 0.87 & 0.10 \\
\hline 1999 to 2001 & 1295 & 0.85 & 0.11 & 0.84 & 0.12 \\
\hline 2000 to 2002 & 1457 & 0.88 & 0.09 & 0.87 & 0.11 \\
\hline 2001 to 2003 & 1650 & 0.91 & 0.08 & 0.90 & 0.09 \\
\hline 2002 to 2004 & 1736 & 0.92 & 0.07 & 0.91 & 0.09 \\
\hline 2003 to 2005 & 1930 & 0.90 & 0.08 & 0.89 & 0.10 \\
\hline
\end{tabular}

Source: Morningstar monthly returns data.

The results show the mean $r^{2}$ and standard deviation of the $r^{2}$ for each individual fund for the 36 month in-sample period under which the Best Fit index (BFI) is estimate based on OLS regressions against each of the 12 Russell Indices and 15 Standard \& Poor's indices' and the RBSA optimisation model using Russell 1000 Growth, Russell 1000 Value, Russell 2000 Growth and Russell 2000 Value. RBSA -BFI is the difference between the respective $r^{2}$ 's

RBSA model: $e_{i}=R_{i}-\left(b_{i 1} F_{1}+b_{i 2} F_{2}+\ldots+b_{i n} F n\right)$

Where; $e_{i}=$ tracking variance, $F_{1} \ldots F n=$ asset classes, $b_{i 1} F_{1}+b_{i 2} F_{2}+\ldots+b_{i n} F n=$ passive style portfolio and $R_{i}=$ fund return. BFI model: ${ }^{r} \mathbf{1}=\alpha+\beta R_{1}+\epsilon_{1}$

Where; ${ }^{r} \mathbf{1}=$ return on fund $1, \alpha=$ constant, $\beta R_{1}=$ return on index 1 and $\boldsymbol{E}_{\mathbf{1}}=$ net effect of all other unobservable factors

Sharpe (1992) and Brown and Goetzmann (1997) state that out of sample tests are the most valid tests for style analysis we therefore turn to out-of sample testing of style classification to evaluate the differences between the methodologies. Using Brown \& Goetzmann's (1997) approach an out-of sample test is formulated for the styles produced which we use to test our different methods of 
returns based style analysis. The basic method runs a regression of dummy variables which represent styles formed in the previous period against fund returns in the following twelve month period (equation 5). Dummy variables are given a categorical value of 1 if a fund belongs to a style group and 0 if they do not belong to that group. Membership of a style class is mutually exclusive and exhaustive.

Out of sample regression equation:

$$
r_{j t}=\alpha+\sum_{i=1}^{8} \beta_{i} \delta_{i t}+\epsilon_{j t}
$$

Where: $r_{j t}=$ fund returns at time $t, \delta_{i}=$ dummy variables 1 to 9 representing membership of each style group with dummy 1 dropped. $\beta_{i}$ = sensitivity coefficient for each fund to each style group, $\epsilon_{j t}=$ error term

The model represented by equation 5 illustrates the Sharpe RBSA model with nine dummy variables whilst the BFI model has the same form but with twenty seven dummy variables representing the number of style indices. For the returns based style analysis RBSA and BFI we form style groups on the basis of thirty six months observed data and then test for twelve months out of sample for each December for the period 2000-2005. This test thus satisfies our criteria of establishing whether funds within a style group behave similarly. 
Table 5: Out of Sample Results for Sharpe Style RBSA Groups and Best Fit Index Groups 1999-2005

\begin{tabular}{|c|c|c|c|c|c|c|}
\hline & $\begin{array}{l}\text { RBSA } \\
\text { adj.r }{ }^{2} \\
\text { monthly } \\
\text { returns }\end{array}$ & $\begin{array}{l}\text { RBSA } \\
\text { adj.r2 } \\
\text { annual } \\
\text { return }\end{array}$ & ANOVA F & $\begin{array}{l}\text { Best-Fit } \\
\text { Index } \\
\text { adj.r }{ }^{2} \\
\text { monthly } \\
\text { returns }\end{array}$ & $\begin{array}{l}\text { Best-Fit } \\
\text { Index } \\
\text { adj.r }{ }^{2} \\
\text { annual } \\
\text { return }\end{array}$ & ANOVA F \\
\hline 1999 & 0.47 & 0.59 & 137.48 & 0.54 & 0.64 & 53.25 \\
\hline 2000 & 0.52 & 0.44 & 90.78 & 0.56 & 0.48 & 32.81 \\
\hline 2001 & 0.38 & 0.52 & 151.73 & 0.38 & 0.53 & 52.68 \\
\hline 2002 & 0.30 & 0.43 & 123.44 & 0.31 & 0.41 & 35.95 \\
\hline 2003 & 0.26 & 0.30 & 79.25 & 0.27 & 0.30 & 27.45 \\
\hline 2004 & 0.30 & 0.31 & 94.08 & 0.32 & 0.35 & 34.74 \\
\hline 2005 & 0.26 & 0.05 & 12.68 & 0.26 & 0.07 & 6.34 \\
\hline Mean & 0.36 & 0.38 & & 0.38 & 0.40 & \\
\hline median & 0.30 & 0.43 & & 0.32 & 0.41 & \\
\hline
\end{tabular}

Cross-sectional regression of annual and monthly out of sample returns of mutual fund against dummy variables signifying membership of a RBSA or BFI style group. Membership of style groups is exhaustive and exclusive. Style groups are formed in the basis of 36 months in sample and tested for the subsequent 12 months out of sample.

$$
r_{j t}=a+\sum_{i=1}^{n} \beta_{i} \delta_{i}+\epsilon_{j t}
$$

Where: $\eta_{j t}^{n}=$ fund returns at time ${ }^{t}, \delta_{i}=$ dummy variables representing membership of style groups where $n=8$ for RBSA and $n=26$ for $\mathrm{BFI}, \beta_{i}=$ sensitivity coefficient for each fund to each style group, $\boldsymbol{E}_{j \mathrm{t}}=$ net effect of all other unobservable factors

The ANOVA F statistic tests the null hypothesis that all slope coefficients are jointly zero. High levels of F statistics reject the null hypothesis that membership of style groups did not explain a significant proportion of out of sample returns of mutual funds belonging to designated style groups. 
Our out of sample results for the two methods of returns based style analysis for the period 1999 to 2005 are presented in Table 5. The appropriate test for statistical significance of this regression with dummy variables is the ANOVA F statistic which tests the null hypothesis that all slope coefficients are jointly zero. The high levels of $F$ statistics that we find in our regression results strongly rejects the hypothesis that membership of style groups does not explain a significant proportion of out of sample returns of mutual funds belonging to designated style groups. When we compare the results for the out of sample tests for the RBSA and BFI style groups we find that in the five out of seven test periods the BFI method performs better than the RBSA method (for both the annual returns regressions and the monthly returns regressions), in other periods they are equal, there is only in the case of the 2002 annual returns (but not monthly returns) out of sample test that the RBSA model performs better. The mean $r^{2}$ for the RBSA and BFI methods are 0.38 and 0.40 respectively for the annual returns of funds regressed against membership of style groups and 0.36 and $\mathrm{BFI} 0.38$ respectively for the monthly cross sectional regressions. ${ }^{\text {iv }}$

We compared our results with Brown and Goetzmann's (1997) for the GSC (cluster methodology) and the Sharpe (1992) RBSA styles which they produced where they recorded a mean $r^{2}$ for the GSC method of 0.30 for the period 1978 to 1994 and a surprisingly low mean $r^{2}$ of 0.08 for the RBSA method. We found that our out of sample results recorded a greater degree of explanatory power not only for the Sharpe coefficient groups but also for our Best Fit Index (BFI) model which recorded the highest level of $r^{2}$ in the comparison. Brown and Goetzmann (1997) produce their GSC categories for mutual funds based on mutual fund returns and their style classification algorithm; their generalised least squares procedure bears great similarities to the k-means cluster methodology which we employed to form the Sharpe style groups. We are of course cognisant of the fact that tests produced in different periods may well produce different results but include the observation to underline the significance of our results. 
Whilst it may appear at first that the clustered RBSA approach may have advantages over a single benchmark due to its ability to combine more than one benchmark this is not the case. Despite the significant improvements the modified RBSA makes over the basic model utilised by Sharpe (1992) and Brown and Goetzmann (1997) it fails to perform as well as the BFI model in the out of sample period. Closer examination of the results highlights some of the compromises that have to be made to meet the exclusivity and exhaustivity requirements of the RBSA model. Selection of the Russell 1000 Growth and Value indices and the Russell 2000 Growth and Value indices precludes the inclusion of the Russell 1000 index and the Russell Mid-Cap indices, as noted previously. Large cap core, equivalent to the Russell 1000 , accounts for between $21 \%$ and $26 \%$ of the sample, depending on the year, as illustrated by Table 2 . Whilst a combination of the Russell 1000 Growth and Russell 1000 Value indices may approximate the Russell 1000 index it may be more difficult to replicate MidCap indices. The sample includes between $25 \%$ and $31 \%$ Mid-Cap funds, of all styles, according to Table 2. This difficulty is highlighted by the existence of a style group in the RBSA results which weights very heavily on Large-Cap Value and Small-Cap Growth, an unlikely combination. This group, which we categorise as Diverse in Table 1, accounts for $5.8 \%$ of the portfolio in 1998 and $9.3 \%$ in 2005.

The $\mathrm{BFI}$ approach is aligned with industry practices and such alignment appears to continue into the period following formation of style groups; funds measure themselves against stock index benchmarks and compete within clearly defined market segments against their peers. Chan et al (2002) and Cremers and Petajisto (2009) amongst others, verify the importance of such benchmarks. The existence of market segments has been known for many years, see Haughton and Pritamani's (2005) comments on the seventies or Bernstein (1999), who defined market segments as groups of stocks that performed similarly over more than one economic cycle, and Menzly and Ozbas (2010) who investigate the effects of investor specialization and market segmentation. Investment practices to exploit these market anomalies can be traced back to the 1930's with Benjamin Graham or T. Rowe Price. Kudish (1995) notes that managers don't change style, even if that style is underperforming, for both business and philosophical reasons. This view is shared by Detzel and 
Weigand (1998) who consider persistence in mutual fund performance. Therefore it seems likely that when a fund belongs to a clearly defined market segment or is benchmarked against a particular style index that it is likely to continue to exhibit these properties into the future.

It should also be noted that style indices or benchmarks have improved dramatically over the period since Sharpe (1992) introduced his RBSA model and started to collaborate with S\&P/Barra to produce style indices ${ }^{v}$. The aim of a style benchmark, as noted by Haughton and Pritamani (2005), is to develop a set of indices that capture the 'investment opportunity set' for managers in the style universes they have identified. The construction methodologies of these indices have become more complex utilising multi-factor models to determine the growth-valuation orientation of component stocks within their universes. The BFI results suggest that they are succeeding in this aim of capturing funds preferences for different combinations of size, value and growth characteristics. These factors are consistent with the superior performance of the BFI model in the out of sample period.

\section{Conclusion}

In this study we consider two methods of returns based style analysis and find that both provide useful insights into mutual fund styles and have a role to play in style analysis. The RBSA method identifies style clusters which are consistent with key market segments and styles widely acknowledged in the equity market, although the requirement for index exclusivity makes it difficult to identify some market segments; notably Mid-Cap styles in our analysis. The BFI method however, by design is structured along the lines of a typical Stylebox; indexes are grouped along the dimensions of size and style. The importance of market segmentation, benchmarking and style persistence may go a long way to explaining the BFI models superior out of sample performance. It 
was also possible using the BFI method to identify some broad trends in the popularity of funds styles, such as the increasing popularity of Small-Cap and Mid-Cap Core styles and the declining popularity of Mid-Cap Growth and Small-Cap Value. The output of the two methods is however different and may be complementary.

The conclusions we reach are as follows; RBSA continues to provide a useful framework for the formation of peer groups particularly if a further layer of analysis, cluster analysis, is used to form style groups based on RBSA coefficients. The inclusion of this further stage shows substantial improvement over the RBSA results reported by Brown and Goetzmann (1997). RBSA can also perform a useful style based performance evaluation function providing historical information on the 'economic exposure' of a fund and may be usefully employed in conjunction with other methods of style analysis such as CBS (Characteristics Based Style) analysis or BFI (Best Fit Index) analysis. Waring and Siegel (2003) advocate RBSA to generate a 'normal portfolio'vi or a customised benchmark which describes the manager's neutral position with respect to style and market risk exposures. We do however find that whilst the RBSA and BFI methodologies perform the peer group evaluation function with similar results in-sample the selection of a Best Fit Index (BFI) or benchmark index from a broad range of style indices performs the peer group and performance evaluation functions more effectively out of sample and it is this out of sample behaviour which is the true test of a style classification system. This result appears reasonable when we consider that the style indices were created and continue to evolve as a means of portfolio evaluation and performance measurement; the same aims as any form of style analysis and recent changes in construction methodologies have also directly tackled the growth-value orientation question. The BFI method also has the advantage of conventional statistical verification of its results which was found to be a criticism of the RBSA method. Future research utilising the results of BFI analysis could include risk measurement or the calculation of information ratios against appropriate style indices rather than 
general market indices, or further development of the Cremers and Petajisto (2009) concept of active portfolio management.

This leads us to conclude that RBSA can capture some of the complexities of style for a single but diversified asset class but is probably better suited to categories of investment where information is less readily available such as asset allocation and hedge funds, Agarwal and Naik (2000), or as a complement to $\mathrm{BFI}$ or $\mathrm{CBS}$ analysis. We believe that a simple Best Fit Index (BFI) model using a single factor methodology is parsimonious and has the advantage of transparency, ease of use and flexibility. We remain cognisant that the $\$ 12$ trillion mutual funds market is an industry providing differentiated pooled investment vehicles and that methods of analysis that build on market practice are of most interest to the average investor in mutual funds. The BFI methodology is intuitively aligned with market practice and provides a useful method of differentiating between funds comprising the asset class which is U.S. Diversified equity mutual funds, allowing both appropriate benchmarking and peer group analysis. 
Appendix 1: The Diversity of U.S. Equity Mutual Funds

Table 6: US Equity Mutual Funds a Heterogeneous Asset Class: Summary Statistics based on Annual Returns 1999-2005

\begin{tabular}{|r|r|r|r|r|r|}
\hline Annual Return & Sample & Mean & Std. Dev. & Min & Max \\
\hline 1999 & 763 & 24.4 & 25.9 & -18.0 & 191.9 \\
\hline 2000 & 908 & 3.3 & 15.3 & -80.4 & 55.2 \\
\hline 2001 & 1126 & -10.9 & 14.9 & -83.9 & 71.6 \\
\hline 2002 & 1295 & -19.7 & 7.5 & -64.5 & 13.3 \\
\hline 2003 & 1457 & 36.4 & 11.5 & -10.5 & 152.8 \\
\hline 2004 & 1650 & 10.2 & 6.0 & -35.3 & 36.8 \\
\hline 2005 & 1736 & 9.8 & 4.9 & -54.5 & 26.6 \\
\hline
\end{tabular}

Source: Morningstar monthly returns data. 


\section{Appendix 2: Stock Market Indices}

We utilise Monthly Returns for the twenty seven U.S. Stock Market Indices. For the RBSA model we use a sub-set of these indices the Russell 1000 Growth, Russell 1000 Value, Russell 2000 Growth and Russell Value indices while for the BFI model we use the full range of twenty seven equity indices as explained in the methodology section.

\section{Table7: U.S. Stock Market Indices}

Russell Indices

Russell Top 200

Russell Top 200 Growth

Russell Top 200 Value

Russell 1000

Russell 1000 Growth

Russell 1000 Value

Russell Midcap

Russell Midcap Growth

Russell Midcap Value

Russell 2000

Russell 2000 Growth

Russell 2000 Value

(Source: Russell and Standard \& Poor's)
S\&P Citigroup Indices

S\&P 500 Composite

S\&P 500 Citigroup Growth

S\&P 500 Citigroup Pure Growth

S\&P 500 Citigroup Value

S\&P 500 Citigroup Pure Value

S\&P 400 Midcap

S\&P Midcap 400 Citigroup Growth

S\&P Midcap 400 Citigroup Value

S\&P Midcap 400 Citigroup Pure Growth

S\&P Midcap 400 Citigroup Pure Value

S\&P 600 Small Cap

S\&P 600 Small Cap Growth

S\&P 600 Small Cap Value

S\&P 600 Small Cap Pure Growth

S\&P 600 Small Cap Pure Value 
Table8: Best Fit Indices Percentage of Funds' Performance Explained by Individual Stock Indices 1996-2005

\begin{tabular}{|c|c|c|c|c|c|c|c|c|}
\hline Best Fit Index & $\begin{array}{l}1996- \\
1998\end{array}$ & $\begin{array}{l}1997- \\
1999\end{array}$ & $\begin{array}{l}1998- \\
2000\end{array}$ & $\begin{array}{l}1999- \\
2001\end{array}$ & $\begin{array}{l}2000- \\
2002\end{array}$ & $\begin{array}{l}2001- \\
2003\end{array}$ & $\begin{array}{l}2002- \\
2004\end{array}$ & $\begin{array}{l}2003- \\
2005\end{array}$ \\
\hline & Percent & Percent & Percent & Percent & Percent & Percent & Percent & Percent \\
\hline Russell 1000 & 18.5 & 18.5 & 11.4 & 15.3 & 15.2 & 23.2 & 20.0 & 16.3 \\
\hline Russell 1000 Growth & 9.2 & 8.7 & 8.6 & 7.2 & 5.7 & 5.8 & 6.5 & 9.0 \\
\hline Russell 1000 Value & 6.2 & 5.5 & 6.0 & 5.6 & 7.4 & 8.4 & 5.9 & 5.5 \\
\hline Russell Top 200 & 1.6 & 1.8 & 8.7 & 6.4 & 7.3 & 2.1 & 3.2 & 3.2 \\
\hline Russell Top 200 Growth & 0.9 & 0.8 & 0.6 & 0.2 & 0.2 & 0.4 & 0.4 & 1.1 \\
\hline Russell Top 200 Value & 0.7 & 0.6 & 0.5 & 0.1 & 0.7 & 0.9 & 1.2 & 1.4 \\
\hline Russell Midcap & 5.2 & 5.5 & 4.7 & 4.5 & 5.1 & 5.6 & 5.9 & 4.8 \\
\hline Russell Midcap Growth & 12.7 & 13.4 & 11.8 & 12.3 & 10.4 & 8.6 & 8.6 & 8.9 \\
\hline Russell Midcap Value & 5.1 & 4.6 & 5.6 & 4.7 & 4.7 & 3.5 & 1.8 & 1.9 \\
\hline Russell 2000 & 2.8 & 2.9 & 3.6 & 3.1 & 3.4 & 4.7 & 6.0 & 5.0 \\
\hline Russell 2000 Growth & 6.4 & 6.9 & 9.3 & 9.1 & 9.8 & 5.5 & 9.1 & 10.4 \\
\hline Russell 2000 Value & 3.8 & 3.5 & 2.0 & 3.2 & 3.7 & 4.2 & 3.4 & 2.1 \\
\hline S\&P500 & 1.7 & 1.9 & 0.9 & 0.8 & 1.1 & 1.0 & 1.6 & 1.9 \\
\hline S\&P500 Growth & 1.8 & 1.8 & 1.4 & 1.6 & 1.4 & 2.2 & 0.8 & 1.6 \\
\hline S\&P500 Pure Growth & 2.9 & 3.3 & 5.0 & 2.9 & 3.4 & 2.5 & 1.8 & 2.4 \\
\hline S\&P500 Pure Value & 0.1 & 0.1 & 0.9 & 0.8 & 0.0 & 0.3 & 0.4 & 1.1 \\
\hline S\&P500 Value & 6.0 & 5.9 & 8.1 & 7.7 & 6.6 & 4.2 & 7.9 & 6.1 \\
\hline S\&P400 & 1.8 & 1.8 & 1.5 & 2.6 & 2.3 & 3.2 & 3.0 & 4.2 \\
\hline S\&P400 Growth & 1.1 & 0.8 & 0.6 & 2.3 & 3.3 & 4.3 & 2.7 & 0.9 \\
\hline S\&P400 Pure Growth & 0.8 & 0.7 & 0.3 & 0.2 & 0.7 & 1.0 & 0.6 & 0.2 \\
\hline S\&P400 Pure Value & 0.3 & 0.3 & 1.4 & 1.5 & 0.8 & 0.5 & 0.5 & 0.6 \\
\hline S\&P400 Value & 0.8 & 0.8 & 2.2 & 2.5 & 3.4 & 1.5 & 2.0 & 4.4 \\
\hline S\&P600 & 1.8 & 2.1 & 0.9 & 1.1 & 0.5 & 2.1 & 2.1 & 1.6 \\
\hline S\&P600 Growth & 2.0 & 2.4 & 0.9 & 1.2 & 1.2 & 2.4 & 2.5 & 1.2 \\
\hline S\&P600 Pure Growth & 1.6 & 1.3 & 0.0 & 0.2 & 0.6 & 0.5 & 0.1 & 0.3 \\
\hline S\&P600 Pure Value & 1.4 & 1.3 & 1.8 & 1.4 & 0.0 & 0.3 & 0.2 & 1.5 \\
\hline S\&P600 Value & 3.0 & 3.1 & 1.2 & 1.5 & 1.2 & 1.3 & 1.8 & 2.7 \\
\hline
\end{tabular}

(Source: Morningstar, Russell \& Standard \& Poor's data 1996-2005)

Results of regressions of 36 months returns regressed on an individual basis against 27 Russell and Standard \& Poor's indices

The Table illustrates the distribution of indices which recorded the highest $r^{2}$ for each individual fund. In most instances, with the exception of the S\&P500, comparable Russell indexes seem to perform the benchmarking function for relatively more funds than the S\&P equivalents this supports Haughton and Pritamani's (2005) assertion that Russell indices are the most widely used by practitioners for benchmarking purposes. 


\section{Appendix 3: Best Fit Indices}

[Table 8 about here]

\section{References}

Agarwal, V. and N. Y. Naik (2000). Generalised Style Analysis of Hedge Funds. Journal of Asset Management 1(1): 93-109.

Barra (1992). New S\&P/Barra "Style" Indexes. Barra News Letter.

Belden, S. and M. B. Waring (2001) Compared to What? A Debate on Picking Benchmarks. Journal of Investing. Winter 2001: 66-72.

Becker, T. (2003). Exploring the Mathematical Basis of Returns-Based Style Analysis. In: T. D. Coggin and F. J. Fabozzi (eds.) Handbook of Equity Style Management. New Jersey: John Wiley and Sons, pp. 435-453.

Belden, S. and M. B. Waring (2001) Compared to What? A Debate on Picking Benchmarks. Journal of Investing. Winter 2001: 66-72.

Ben Dor, A., R. Jagannathan and I. Meier (2003). Understanding Mutual Fund and Hedge Fund Styles Using Return-Based Style Analysis. Journal of Investment Management 1(1): 94-134.

Bernstein, R. (1999). Style Investing: Unique Insight into Equity Management. New York, Wiley Brown, S. J. and W. N. Goetzmann (1997). Mutual fund styles. Journal of Financial Economics 43(3): 373-399.

Chan, L., K., H.-L. Chen, and J. Lakonishok (2002). On Mutual Fund Investment Styles. Review of Financial Studies 15(5): 1407-1437.

Chan, L., K., S.G. Dimmock, and J. Lakonishok (2009) Benchmarking Money Manager Performance : Issues and Evidence Review of Financial Studies 22(11): 4553-4599.

Christopherson, J. A. (1995). Equity Style Classifications: Adventures in Return Pattern Analysis Journal of Portfolio Management (Spring): 32-43.

Cremers, M., and A. Petajisto (2009) How Active is Your Fund Manager? A New Measure That Predicts Performance Review of Financial Studies 22(9): 3329-3365.

Cremers, M., A. Petajisto, and E. Zitewtz (2010) Should Benchmark Indices Have Alpha? Revisiting Performance Evaluation. EFA 2009 Bergen Meetings Paper; AFA 2010 Atlanta Meetings Paper: http://ssrn.com/abstract=1108856 
Del Guercio, D., and P. A. Tkac (2008) Star Power: The Effect of Morningstar Ratings on Mutual Fund Flows Journal of Financial and Quantitative Analysis 43(4):907-936.

Detzel, F. L. and R. A. Weigand (1998). Explaining Persistence in Mutual Fund Performance. Financial Services Review 7(1): 45-55

Federal Reserve Statistical Release: Selected Assets and Liabilities of Commercial Banks in the United States - H. July 1, 2011.

Gruber, M. J., (1996) Another Puzzle: The Growth in Actively Managed Mutual Funds Journal of Finance 51(3):783-810.

Haughton, K. and M. Pritamani (2005). US Equity Style Methodology. Russell Research Commentary (August 2005).

Investment Company Institute (2011) 2011 Investment Company Fact Book.

Kaplan, P. D., J. A. Knowles, and D. Phillips (2003). More Depth and Breadth than the Style Box: The Morningstar Lens. In: T. D. Coggin and F. J. Fabozzi (eds.) Handbook of Equity Style Management. New Jersey: John Wiley and Sons, pp. 131-157.

Kudish, D. J. (1995). Reversing Manager-Selection Failure: Using Style Allocation to Improve Fund Returns. In R. A. Klein and J. Lederman eds. Equity Style Management: Evaluating and Selecting Investment Styles. Chicago-London, Irwin Professional Publishing,pp. 399-420.Kuenzi D.E. (2003) Strategy Benchmarks from the Investment Manager's Perspective. Journal of Portfolio Management Winter 2003: 46-56.

Lehmann, B.N., and D. M. Modest (1987) Mutual Fund Performance Evaluation: A Comparison of Benchmarks and Benchmark Comparisons Journal of Finance (42)2: 233-265.

Menzly L. and O. Ozbas (2010) Market Segmentation and Cross-predictability of Returns Journal of Finance 65( 4):1555-1580

Sharpe, W.F. (1964) Capital Asset Prices: A Theory of Market Equilibrium Under Conditions of Risk Journal of Finance 19(3):425-442.

Sharpe, W. F. (1992). Asset Allocation: Management Style And Performance Measurement. Journal of Portfolio Management Winter: 7-19.

Sirri E. J., and P. Tufano (1998) Costly Search and Mutual Fund Flows Journal of Finance 53(5): 1589 $-1622$.

Standard \& Poor's(2006) Standard \& Poor's U.S. Style Indices Index Methodology April 2006.

Swinkels, L. and P.J. Van Der Sluis (2006) Return- Based Style Analysis with Time-Varying Exposures. The European Journal of Finance 12(6): 529-552. 
ter Horst, J. R. , T. E. Nijman, and F.A. de Roon (2004). Evaluating Style Analysis. Journal of Empirical

Finance 11: 29-53.

Waring, M. B. and L. B. Siegel (2003). The Dimensions of Active Management. Journal of Portfolio Management Spring: 35-51.

\footnotetext{
'We selected Russell Indices for our RBSA because the correlations between similar Standard \& Poor's and Russell Indices were very high but the Russell Style indexes contained less potential for overlap than the Standard \& Poor's indexes. They are also used extensively in similar studies e.g. Ben Dor et al. (2003) used the Russell 1000 and Russell 2000 style indices in their analysis and Chan et al (2002) noted that Russell indexes are the most commonly used style benchmarks use in this type of study. We have chosen to use a small number of indices as increasing the number of indices e.g. using the Standard \& Poor's variants which give the same coverage added nothing to the model. Ben Dor et al (2003) rationalised the use of a small number of asset classes due to the problems of optimization, correlation and robustness of results.

ii Becker (2003) reviews the different mathematical properties of these different approaches.

iii Results for years not illustrated in Table 1 are available on request.

iv More detailed results for cross-sectional regressions on annual returns are available on request. It should also be noted that the Brown \& Goetzmann (1997) results also recorded one very low year 1986 (GSC $r^{2}$ only 0.08).

"See Barra (1992) 'New S\&P/Barra "Style" Indexes' for details.

vi A 'normal portfolio' is a universe of securities that contains all the securities from which a manager normally chooses, weighted as the manager would weight them in a portfolio. Christopherson (1998) notes that there can however be more than one 'normal portfolio' or specialised index for a given fund manager.
} 